\section{REGIONAL REPORTS}

\section{Canals and chasms}

Thank you, Amsterdam. Roll on, Delhi! This is the best way in which I can express what I felt at the close of the one day ISCAIP conference in May. Amsterdam itself was a joy and must rank as one of the most appealing cities in the world. I certainly felt safe walking alongside the canals and through the city centre at all times of the night-a privilege I have not experienced in South Africa for many years now. The meeting was also a wonderful opportunity to meet with fellow global villagers whose enthusiasm for child safety provides constant inspiration, even though perspectives in terms of what is desirable, and what is tangible, may differ among us, depending on the region of origin.

In his presentation on passenger safety, fellow ISCAIP delegate Professor Krishnan described the obstacles in promotion of child restraints in Malaysia, his experience being very similar to ours in South Africa. Another increasing problem common to both countries is the unchecked importation of hazardous toys, domestic appliances, and other goods from both Eastern and Western countries. In South Africa, the prevalence of such "grey" imports is one inevitable outcome of increasingly relaxed importation controls and a flourishing informal retail sector, itself the result of persistently high unemployment. One national newspaper recently reported on an investigation into toys widely available from street hawkers in Johannesburg. The sound level of a toy cellphone manufactured in the orient measured $91.1 \mathrm{~dB}$, and that from a guitar shaped "melody maker" measured $104.4 \mathrm{~dB}$. The maximum noise level permitted in industry is $85 \mathrm{~dB}$, on average over eight hours. Regrettably, there is no legislation in South Africa pertaining to noise levels of toys.

Progress in providing electricity to poorer residential areas has also unleashed a flood of substandard, frankly hazardous electrical appliances on to the retail market. Plastic appliances manufactured without fire retardant, faulty television tubes which explode instead of imploding, and circuit boards which emit toxic gas when overheated are three examples of manufacturing "short cuts" taken simply to maintain the maximum credit margin. An investigation by another daily newspaper revealed that such dangerous appliances stand proudly on the shelves of several popular supermarkets, despite the management of these outlets insisting that all new appliances are subject to approval by the South African Bureau of Standards. So even the improved domestic safety which should be heralded by electrification carries a new risk, one that is simply born out of greed and exploitation of opportunities created by consumer demand, and glaring holes in safety legislation.

Dr Khadija Jaffer has been awarded an MPhil degree for her dissertation on child safety in 33 crêches and other daycare centres situated in low income areas. Her main findings included a fairly uniform standard of safety awareness among caregivers and envi- ronmental safety features, regardless of fees charged. Although the majority of injuries recorded in the study were fairly trivial, there appeared to be no standard procedure for recording injury events, and crêche staff were clearly concerned about the negative publicity that might accrue from disclosure of such records. Once again, economic considerations to the fore, always likely to eclipse consideration for the safety of a child who is both vulnerable, and economically powerless.

DAVID BASS

Department of Paediatric Surgery, Red Cross War Memorial Children's Hospital, Rondebosch 7700, South Africa (tel: +2721658 5199,fax: +2721689 1287, e-mail:daveb@redxch.wcape.gov.za)

\section{Australian reports}

Australian drowning prevention strategy

"We know that over 300 Australians will drown this year. We know this because over 300 Australians drown every year. Drowning is the third largest cause of accidental death in Australia overall and in the $0-5$ age group is the number one killer. And the real tragedy of drowning is that almost every drowning is preventable". Rob Bradley, Royal Life Saving Society, opening the National Water Safety Conference, May 1998, Melbourne.

It is little news to anyone that Australia has a problem with drowning-over the past 20 years toddler drowning in domestic pools has been a focus of prevention by injury specialists-but to date there has been no concerted action across all drowning issues. With the formation of the Australian Water Safety Council this will change.

The council was formed in February 1998 as the result of representation to, and with the strong support of, the Federal Minister responsible for sport, Andrew Thompson. It is intended to act as a consultative forum comprising the major water safety and related government agencies and includes rescue and swim training organisations, such as the Royal Life Saving Society, Surf Life Saving Australia, AUSTSWIM, safety groups such as Farmsafe and Kidsafe, and key government associations such as the Local Government Association.

A conference was held by the council in May to design an action plan to maximise the cooperation between water safety organisations and the various tiers of government to ensure that effective strategies are enacted that avoid duplication and maximise the impact of available effort.

The National Water Safety Plan is intended to:

- Identify and prioritise the major water safety issues;

- Establish the Water Safety Standards to be applied nationally;

- Commit to support, bolster, and improve the expertise, programs, and resources that are already operating within the system;

- Identify and maximise organisational linkages to ensure that duplication of effort and resources are avoided and so that positive ideas and best practices are shared throughout Australia.

The key result areas identified and addressed by the plan are:
Water Safety Research-primarily collation of existing data and establishment of a research coordinating body;

Management of aquatic locations - the first steps will be standards for new locations and safety audits of existing aquatic locations;

Water safety education - focusing on coordinating efforts in schools and standards and accreditation of teachers and programs;

Targeting of key drowning demographics - the plan sets specific areas of work for children under 5 years; traditional risk takers, males 16-35 years; rural communities; tourists; and culturally diverse communities.

"The prize for successfully implementing this National Water Safety Plan is immenseindeed the prize is ... life itself! ... the saving of up to 300 Australian lives per year".

Toddler drownings

About 70 Australian children under 5 drown each year. For every drowning death about six children are admitted to hospital because of an immersion incident, with up to $20 \%$ of these children having long terms problems. On these figures between 20 and 90 children a year will suffer brain damage as the result of nearly drowning.

Swimming pools represent the main risk and are the location of about half the child drownings among children under 5 . In the five years to 1996,157 children drowned in home pools-30\% because there was no fence, $24 \%$ where there was direct access from the house to the pool, $18 \%$ where a gate was propped open, $15 \%$ where there was a defective gate, $6 \%$ where there was a defective pool fence, and $6 \%$ where the child climbed the side of an above ground pool.

Apart from swimming pools the 315 toddler drownings in the five years to 1996 were made up of 49 deaths in lakes and dams, 40 in baths, 20 in objects containing water, 11 in rivers, and 38 in other circumstances.

While there has been a reduction in drowning deaths in toddlers associated with efforts to fence swimming pools and the large amount of publicity about this, there has been an upward trend recently. There were 78 deaths in 1992, 53 in 1993,40 in 1994, and in 1995 and 199668 in each year.

Sources: (1) National Water Safety Conference: Papers. Melbourne: Australian Water Safety Council, 5 May 1998. (2) Australian Water Safety Council. National water safety plan: fostering cooperation and commitment in the fight against drowning. July 1998. (3) Royal Life Saving Society of Australia. Keep watch: the national drowning report, 1997 edition. Sydney.

Speed as dangerous as alcohol

Alcohol as a major risk factor for motor vehicle accidents and injury is well known and documented. The level of risk of accident, injury, and death rises quickly with the amount of alcohol and small increases in the alcohol level bring large increases in the risk of injury. A new Australian study has shown that relatively small increases in speed have exactly the same effect on the risk of accident and injury. ${ }^{1}$

The Road Accident Research Unit at the University of Adelaide studied 151 cases where passenger cars were involved in crashes. By reconstructing the events associated with the crash and comparing them to other cars that had not crashed they were able to estimated that the risk of a crash doubled with each $5 \mathrm{kph}$ increase in speed. 
They concluded that "speeding in an urban area is as dangerous as driving with an illegal blood alcohol concentration (BAC). Even travelling at $5 \mathrm{kph}$ above the $60 \mathrm{kph}$ limit increases the risk of crash involvement as much as driving with a BAC of 0.05 ".

The authors found that the majority of drivers actually drive in the speed range from 61 to $74 \mathrm{kph}$ and that the risk of a crash driving at $65 \mathrm{kph}$ is about the same as driving with $0.05 \mathrm{BAC}$; the risk of a crash driving at $68 \mathrm{kph}$ is about the same as driving with 0.08 $\mathrm{BAC}$; and the risk driving at $72 \mathrm{kph}$ is about the same driving with a BAC of 0.12 .

In the light of this finding they found it incongruous that, while the risk of driving at $72 \mathrm{kph}$ is about the same as driving with a BAC of 0.12 , the penalty for the drink driving is a $\$ 500-\$ 900$ fine and automatic disqualification of driving license for six months but the penalty for speeding is only a $\$ 100$ fine.

Speed and stopping distance: the extra $10 \mathrm{kph}$ counts!

The Road Accident Research Unit study quoted studies showing that it takes about 1.5 seconds for a driver to react to a problem and start to brake. At $60 \mathrm{kph}$ this means the car will have travelled 25 metres before the brakes are applied; at $70 \mathrm{kph}$ it rises to 29 metres. Once the brakes are applied an emergency stop at $60 \mathrm{kph}$ takes 24 metres and at $70 \mathrm{kph} 31$ metres. Therefore a car travelling at $60 \mathrm{kph}$ requires 49 metres to make an emergency stop and a car travelling at $70 \mathrm{kph}$ needs 60 metres.

The authors note that this underestimates the importance of the extra $10 \mathrm{kph}$ of speed and give the example of two cars travelling side by side, one at 60 the other at $70 \mathrm{kph}$. If a child were to step out 49 metres in front of the slower car which just manages to stop in time the faster car would still be travelling at $45 \mathrm{kph}$.

This means that the extra $10 \mathrm{kph}$ would mean the difference between no accident and one where the child was hit by a car travelling at $45 \mathrm{kph}$.

1 Kloeden CN, McLean AJ, Moore VM, et al. Travelling speed and the risk of crash involvement. Canberra: Federal Office of Road Safety, 1997 (CR 172).

IAN SCOTT

Kidsafe Australia,

Suite 4, Level 1, 230 Church Street, Richmond, Victoria, Australia (tel: +6139427 1008,fax: +61394213831, e-mail:iscott@peg.apc.org)

\section{Injury to Maori}

As was noted in a previous regional report there has been considerable interest in establishing the incidence and pattern of indigenous groups in both Australia and New Zealand. The Injury Research Unit and Ngai Tahu Maori Health Research Unit have published such a resource document for Maori injury.

That injury is a leading cause of mortality and morbidity among Maori has long been known. The report provides detailed graphs and tables for mortality and morbidity by age and by cause.

The rates for Maori are higher than those for New Zealand as a whole. In the period 1985-94, injury deaths among those under 1 totalled 73.9 per 100000 among Maori, more than double the figure for New Zealand as a whole (33.2). The difference in death rate is not as marked for older children and for those aged 1-14 years the figures are 17.5 and 16.6 respectively.

Injury represents $5 \%$ of deaths for Maori children under 1 year of age, $59 \%$ for those aged 1-4 years, and 56\% for those aged 5-14 years. Assault represents $12 \%$ of injury deaths for children under 1 year; this is about the same percentage as assault $(5 \%)$ and self inflicted $(6 \%)$ categories combined among those aged 5-14 years. Injury hospitalisation represents $7 \%$ for children under 5 years and $26 \%$ for those aged 5-14 years. Assault represents $11 \%$ of injury hospitalisation ( $1 \%$ undetermined) for Maori children under 1 and, for Maori children 1-14 years, assault is $3 \%$ and self inflicted $1 \%$.

As causes of injury death among Maori children aged $1-14$ years, motor vehicle traffic $(47 \%)$, pedestrian, other $(6 \%)$, fire/burn $(15 \%)$, drowning (16\%), suffocation (11\%), and falls $(5 \%)$ are the leading causes. As causes of injury hospitalisation among the same group the causes are: fall (41\%), fire/burn $(8 \%)$, hot object/substance $(6 \%)$, struck by/against $(9 \%)$, cut/pierce $(8 \%)$, motor vehicle traffic $(13 \%)$, poisoning $(8 \%)$, and other specified causes (7\%).

Sources: (1) Injury hospitalisation among indigenous Australians (regional report). Inj Prev 1997;3:229. (2) Langley J, Broughton J, Nga Tatauranga: injury to Maori. Dunedin: Injury Prevention Research Unit, University of Otago, June 1998 (OR21). (3) Langley JD, Smeijers J. Injury mortality among children and teenagers in New Zealand compared with the United States of America. Inj Prev 1997;3:195-9.
JOHN LANGLEY

Injury Prevention Research Unit,

Department of Preventive and Social Medicine,

University of Otago, PO Box 913,

Dunedin, New Zealand

(tel: +64 3478 8342, fax: +6434798337,

e-mail:iprunz@otago.ac.nz)

\section{LETTER TO THE EDITOR}

Little boys and dangerous toys

EDITOR,- - I am a regular reader of Injury Prevention and enjoy the amusing pieces used as page fillers. I recently came across a poem in an old poetry book I had used in my junior high school days and thought that readers might be interested.

George, written by Hilaire Belloc*, tells the tale of George who was given "an immense baloon" by his grandmother, "but when it came, it got into the candle flame, and being of a dangerous sort exploded with a loud report". The poem goes onto describe the ensuing mayhem and has the moral that "little boys should not be given dangerous toys".

I have a particular interest in the poem as I am a fire inspector who coordinates a child firesetter intervention program. Unwittingly or otherwise the grandson is the most identifiable "culprit", but the grandmother (adult) is the focus for the moral.

It is not uncommon for grandchildren to use their grandparents' lighters (regardless of who is visitng whom)-especially if the child has not had such free access to them before. A recent incident here in Edmonton involving a 3 year old grandchild using his grandmother's lighter to ignite a $\$ 70000$ fire makes this point poignantly.

RUSTY FOERGER Coordinator, Child Firesetters Project, Emergency Response Department, Public Safety and Education Branch, \#301, 12220 Stony Plain Road, Edmonton, Alberta T5N 3Y4, Canada

$\star$ Belloc (1870-1953) was born in France but became a naturalised British subject and was a poet, historian, and essayist. 